\title{
DIFERENCIAS TERMINOLÓGICAS Y CONCEPTUALES ENTRE QUASI POSSESSIO IURIS Y QUASI POSSESSIO REI.
}

\author{
FERMÍN CAMACHO DE LOS RÍOS \\ Titular de Universidad de Derecho Romano.
}

Una distinción necesaria que gran parte de la doctrina parece no considerar, es la que podemos establecer entre la elástica y ambigua expresión quasi possessio y la quasi possessio iuris. En otros términos, las diferencias entre la quasi possessio iuris y la quasi possessio rei, así como resaltar que ambas expresiones se suelen simplificar en la confusa conceptualización quasi possessio.

Comocuestión previa debemos indicar la doctrina elaborada por ALBERTARIO ${ }^{1}$ y PEROZZI ${ }^{2}$ en torno a esta materia: ambos coinciden en señalar que es extraña al derecho clásico la noción de la posesión de la servidumbre, del usufructo y de la superficie que, sin embargo, fue introducida por los postclásicos. Estos habían adoptado la terminología posesoria, hablando de possessio o de quasi possessio en estas situaciones de hecho. Motivo por el que las relaciones de servidumbre y de usufructo eran tratadas en el mismo plano que la posesión, implicando, esta nueva consideración, innumerables consecuencias prácticas: una aplicación de una tutela interdictal más allá de los límites que habían dispuesto el pretor y la jurisprudencia clásica, otorgando, en algunos casos, a la posesión de derechos una extensión de los interdictos posesorios, de la actio Publiciana, y de la Longi temporis praescriptio; asimilando, en resumen, la quasi possessio iuris a la clásica possessio rei.

Estas tesis no pueden ser atacadas en sustancia, aunque se debe señalar que por cuanto refiere al usufructo y a la superficie, las argumentaciones de ALBERTARIO y Perozzi se plantean en dos planos diferentes, así como que las conclusiones no corresponden puntualmente ni a las premisas ni a los resultados.

En realidad, los planteamientos de estos autores, sobre el análisis de la posesión de derechos, se presentan como una indagación sobre una construcción dogmática en el derecho romano, de esta forma afirman que hay un gran número de textos donde se habla de la imposibilidad de poseer las res incorporales, llegándose a concluir que la jurisprudencia clásica no pudo construir una estructura posesoria para el ejercicio

${ }^{1}$ ALBERTARIO, Studi II, pag. 308-490.

${ }^{2}$ PEROZZI, I modi pretori di acquisto delle servitú, en «Riv. it. per le sc. giuridiche». 1987. 
de hecho de los derechos ${ }^{3}$. Los términos de la indagación se van enturbiando sin embargo en el transcurso de la investigación: ya que, examinando la cuestión -en el aspecto relativo a la posesión del usufructo, del uso y de la habitatio-el problema inicialmente propuesto se funde y se confunde con otro bien diferente, como es el que se refiere a las relaciones entre el usufructuario, el usuario, y el habitator —en cuanto titulares de derecho-y la cosa sobre la que éstos derechos se ejercitan; textos que tratan de la posesión de la cosa en usufructo $-\mathrm{y}$ consecuentemente de la posibilidad de considerar una deiectio y de gozar, por esta causa, de una protección posesoria - que son utilizados indistintamente junto a otros donde se considera, muy al contrario, la posición de quien ejercita un derecho del cual carece de titularidad — situación del cesionario del derecho—; estas alteraciones encuentran fundamento y demostración en los mismos presupuestos, así como sirven para demostrar la tesis fundamental. En resumen se entrecruzan dos problemas que tienen distinta naturaleza jurídica.

Será en virtud de estas consideraciones como Albertario llega a conclusiones como:

Mientras en la edad clásica el usufructurario, el usuario y el habitator eran solamente detentadores, en la edad postclásica y en la justinianea éstos tenían la detentio rei y la possessio iuris, es decir, la posesión del derecho que tenían sobre la cosa de otro ${ }^{4}$.

En el tiempo de Justiniano el usufructuario, el usuario, el habitator, tienen siempre la detentación de la cosa sobre la que el derecho se ejercita, están in possessione nomine alieno, pero también tiene una possessio nomine propio, es decir, la possessio iuris, la posesión de su derecho de usufructo, de uso o de habitatio ${ }^{5}$.

La legislación justinianea configura la superficie como un ius in re: crea mediante numerosas interpolaciones, la possessio iuris opuesta a la clásica posssessio rei: porque al tener un ius in re, se dice que el usufructuario, el usuario y el habitator, enfiteuta y superficiario, tienen una quasi possessio o una possessio iuris ${ }^{6}$.

En cuanto a su naturaleza jurídica, es decir, las relaciones entre los titulares de un ius in re y la cosa sobre la que se ejercita el derecho, nosotros, sin embargo, podemos descubrir la situación de un tercero -que podemos denominar cesionario- y a tal punto la possessio iuris, en contra de ALBERTARIO, se nos presenta

${ }^{3}$ ALBERTARIO, Studi di diritto romano, Milán 1933-1953, pág. 309, 339-340.

${ }^{4}$ ALBERTARIO, Studi II, cit. pág. 329.

${ }^{5}$ Como se desprende del Vat. fragm. 90; así como también lo indica ALBERTARIO en Studi II, pag. 371 y ss; así como SCHERILLO en Rend. Ist. lomb. 63 (1930) pag. 525.

${ }^{6}$ ALBERTARIO, Studi II, cit. pag. 434. 
como un concepto más restringido que caracteriza la posición de quien ejerce de hecho un derecho del cual él no es titular, y no, como indica este autor, «como la expresión que describe la posición del mismo usufructuario, usuario, etc., los cuales en derecho justianianeo unían la detentación de la cosa con la posesión del derecho».

Será en razón de estas conclusiones cuando podemos comprobar si se responden a las premisas que el propio ALBERTARIO - y en su línea casi la globalidad de la doctrina- había establecido. Por cuanto se refiere, a la distinción hecha entre todos aquellos casos en los que, existiendo una relación de material de detentación entre el titular de un derecho y la cosa sobre la que este derecho se ejercita, por un lado se necesita establecer la cualificación jurídica de tal relación material, mientras que por otro se descubría el problema de la cualificación del ejercicio de hecho de este mismo derecho; se trata de ver como en el derecho romano, en el cotejo de sus fuentes, se deslindan estas dos cuestiones.

Como ya hemos indicado, ALBERTARIO - junto a gran parte de la doctrinaidentifica, en todos los casos, quasi possessio rei, y quasi possessio iuris, entendiendo siempre la una y la otra como expresiones que describen el ejercicio de hecho de un derecho, que los compiladors revestían con la terminología posesoria, y que solían simplificar en la ambigua expresión quasi possessio.

Que no siempre la expresión quasi possessio es identificable con possessio iuris - y viceversa - es algo que ya señala BONFANTE ${ }^{7}$, quien, acogiendo en sustancia la crítica que realiza ALBERTARIO — parte de sus conclusiones-, reconoce que, en el campo de las servidumbre prediales, el concepto de la possessio iuris representaba una creación de corte justinianeo: aunque conseideraba que, para el ususfructo, los compiladores habían afirmado no ya la possessio iuris sino una verdadera y propia possessio.

A pesar de estas consideraciones, y siguendo a SARGENTI ${ }^{8}$, comprobamos que Bonfante, enmendando la tesis de ALBERTARIO, peca a su vez de unilateralidad: es cierto, en efecto, que la quasi possessio no se identifica siempre con la quasi possessio iuris, aunque, también es cierto, que BONFANTE no advierte que esta identificación sí aparece en algunos textos.

En el campo del usufructo, así como también en el de la superficie, la obra de los compiladores justinianeos había reconocido al usufructuario y al superficiario la posesión de la res, textos que hablan, en diversos pasajes, de quasi possessio ususfructus o también de possessio usufructus.

El propio BONFANTE, en base a un amplio cotejo de textos y fuentes, llega a la conclusión en esta materia que en la compilación justinianea aparecen como una «forma híbrida» ${ }^{9}$ por una lado quasi possessio y por otro possessio naturalis, al igual que indica Ricobonno ${ }^{10}$.

${ }^{7}$ BONAFANTE, Corso di diritto romano III. Diritti reali, cit. pag. 208.

${ }^{8}$ SARGENTI, Sulla quasi possessio e la possessio iuris, cit. pag. 228.

${ }^{9}$ BONAFANTE, ops. cit. pag. 221.

${ }^{10}$ RICOBONO, Traditio ficta Z. S. S. 1913, pag. 162 y ss. 
De esta forma, señalando la gran dispersión terminológica, se pone de manifiesto la multiplicidad y complejidad de los conceptos - como se denota a través de un examen de los textos- $-\mathrm{y}$, aunque autores más recientes advierten la diversidad de los dos problemas —quasi possessio iuris y quasi possessio rei-, no son sin embargo capaces de mantener siempre clara tal distinción.

GROSSO, así como parte de la doctrina ${ }^{11}$, nos intenta plantear con precisa determinación los dos prolemas: así por un lado dice «i romani non riconobbero all'usufruttuario la vera e propia possessio», $\mathrm{y}$, por otra parte, nos indica que no se pudo en derecho clásico «construire un possesso del diritto di usufrutto», al punto que advierte que la quasi possessio —expresión para él ya utilizada por la jurisprudencia clásica - indica la relación del usufructuario con la cosa. Aunque después, analizando la nueva concepción de derecho postclásico, terminada la distinción entre los interdictos directos y los útiles, así como producida la asimilación de la especie quasi possessio en el género possessio - como elementos básicos que concurren a la formación del concepto de la quasi possessio usufructus-concluye observando que: el proceso de transformación que se va operando en el derecho romano habría podido desembocar en el reconocimiento de la posesión de la cosa al usufructuario, aunque los justinianeos lo conducían a otra conclusión, aplicando el concepto de quasi possessio y después de possessio al usufructo mismo, es decir al derecho.

De esta forma GROSSO logra fundir y resumir en un solo los dos procesos que estaban inicialmente considerados como distintos.

Pero no es sólo GROSSO quien realiza tales elásticas conclusiones, en términos muy parecidos se expresa BIONDI, quien, en el tema de las superficies advertía que el pretor, con el interdictum superficiebus no protegía siempre al titular de la superficie, sino que lo que tutelaba era «in certo senso e indirettamente viene tutelato lo stato dei fatto», es decir, se articula una defensa independiente de la titularidad ${ }^{12}$.

CARCATERRA ${ }^{13}$ al igual que GROSSO y BIONDI se ha ocupado de la materia con importancia dentro de la doctrina, realizando varias investigaciones en torno a la possessio iuris y a la quasi possessio. Este autor, así como la mayor parte de la doctrina, encuentra la predicha confusión inadvertida, es decir, el problema de la distinción entre la posesión de la res y el de la poeseión del mismo derecho: confusión en los textos cuando hablando de la possessio libertatis, acude a un análisis paralelo al que estudia los pasajes que se refieren a la posición del usufructuario en relación con la cosa ${ }^{14}$. Disparidad en los conceptos cuando, estudiando la possessio usufructus, después de haber establecido que ésta es una construcción justinianea

${ }^{11}$ GROSSO, Corso di diritto somano - L'usufrutto. Turín, 1935. pag. 231 y ss.

Usufrutto e figure affini nel diritto romano. Turín, 1958, pag. 333 y ss.

${ }^{12}$ BIONDI, Categoría romana delle servitutes, Milano 1937, pag. 467 y 470.

${ }^{13}$ CARCATERRA, Il possesso dei diritti nel diritto romano, Milán, 1942, y en Il possesso, Roma 1967.

${ }^{14}$ CARCATERRA, Il possesso dei diritti, cit. pag. 49. 
—no sólo porque rompe el dogma clásico possideri non possunt nisi quae sunt corporalia, sino también por el carácter de la posesión romana, que es soberanía-, sigue diciendo «e l'usufruttuario non puó aspirare a tanto: il suo godimento presuppone necessariamente l'altrui sovranitá» ${ }^{15}$, reduciendo la discusión al problema de la situación del usufructuario frente a la res o frente al nudo propietario, para cambiar, poco después, a tratar de la posesión del cesionario del usufructo. Como apreciamos otra disfunción cuando afirma, en líneas generales, «Il possesso, allora, diventa esercizio di un diritto, cioé possessio di un diritto» ${ }^{16}$, mientras que ya sabe-mos que no todo el ejercicio de un derecho tiene la capacidad de perfilarse con ras-gos posesorios. Evidentemente, el titular de un derecho no necesita poseer el mismo - la titularidad del derecho hace innecesaria implícitamente su posesión.

A través de los planteamientos anteriores queremos poner de relieve la idea que la quasi possession iuris y la quasi possessio rei no son, necesariamente, expresiones idénticas; la quasi possessio iuris no es siempre la exteriorización del derecho del cual se es titular, sino una expresión que reviste de aspectos posesorios al ejercicio de hecho de un derecho del que se carece del título; y éste será el eje básico de distinción entre ambas instituciones; aunque terminológicamente las fuentes, en numerosas ocasiones, utilicen la elástica expresión quasi possessio para recoger estas dos bien diferentes situaciones de hecho.

Un campo donde se ve esta multiplicidad de cuestiones, la distinción entre la quasi possessio rei y la quasi possessio iuris, así como la evolución jurídica de los conceptos desde el derecho clásico al derecho justinianeo, es en el usufructo, donde, con frecuencia, se perfilan en la ambigua y escueta expresión quasi possessio ambos supuestos.

Una aproximación a esta complejidad se logra con la lectura de D. 43, 17, 4: D. 43, 17, 4 (Ulp. Lib. LXX ad ed.) In summa puto dicendum et inter fructuarios hoc interdictum reddentum: et si alter usum fructum, a alter possessionem sibi defendat, idem erit probandum et si usus fructus quis sibi defendat possessionem, et ita Pomponius scribit perinde et si alter usum, alter fructum sibi tueatur, et his interdictum erit dandum.

Este texto se encuentra alterado por los compiladores, y de él debemos destacar varias cuestiones; en su primera parte el problema que viene examinado es: si el interdicto es concedido en disputas entre usufructuarios o entre el usufructuario y el poseedor; mientras que en la segunda parte del pasaje, por el contrario, se afirma que el interdicto es aplicable et si ususfructus quis sibi defendat possessionem.

Distinguimos un doble orden de problemas: de un lado la posición, frente a un interdicto de naturaleza posesoria del titular del usufructo, y por otro de quien

${ }^{15}$ CARCATERRA, opus. cit. pag. 72.

${ }^{16}$ CARCATERRA, Il possesso dei diritti, cit. pag. 169. 
ejercita de hecho un usufructo del cual no es titular su poseedor. Estos dos problemas que aparecen en el texto, sobre la aplicación del interdicto uti possidetis, son propuestos más genéricamente en referencia a las relaciones entre el usufructo y la posesión.

En relación con estas dos cuestiones - situación de quasi possessio rei y de quasi possessio iuris - existen abundantes textos clásicos, en donde se omiten o se excluyen para el usufructo los efectos de la posesión. Textos donde, además de prohibir al usufructuario tener la posesión, contraponen el uti frui al possidere: el usufructuarionon possidet, sed habet ius utendifruendi (Gayo. Inst. II, 93): ususfructus nomine rem tenet, quamvis nec hic utique possideat

D. 10, 4, 5, 1 (Ulpianus Lib. XXIV ad Ed.) ...Et ait, priorem quidem sie, ut actor possessionem habeat, is autem, eum quo agetur, rei servandae causa sit in possessione; eum vero, qui usufructum habeat, sie ut actor rem possideat, is, eum quo agetur, utatur fruator D. 7, 1, 60, 1 (Paulus Lib. V Sententiarum) Si fundus, cuius ususfructus petitur, nom a domino possideatur, acti redditur. Et ideo si de fundi propietate inter duos quaestio sit, frustuaris nihilo minus in possessione esse debet, satisque ei a possessore cavendum est, quod non sit prohibiturus frui eum, cui ususfructus relictus est, quamdiu de iure suo probet. Sed si ipsi usufructuario quaestio moveatur, interim usufructus ei aufertur; sed caveri de restituendo eo, quod ex his fructibus percepturus est, vel si statis non detur, ipse frui permittitur.

D. 43, 26, 6,2 (Ulp. Lib. LXXI ad Ed.) Is, qui rogavit, ut precario in fundo moretur, non possidet, sed possessio apud eum, qui concessit, remanet, nam et fructuarius, inquit, est colonus, et inquilinus sunt in praedio, et tamen non possident non possidet.

A través de estos pasajes se desprende el pensamiento genuino de la jurisprudencia clásica, para ella el ejercicio de hecho del derecho de usufructo es absolutamente independiente de la posesion, ya que, por el contrario, puede existir, y generalmente existe, una coexistencia con la posesión de otro - fruto de la extensión del dominio-: además de ser un ejercicio con una protección diferente que el de la possessio.

Son textos que excluyen, respecto del usufructo, los efectos que son propios de la possessio, como son la protección interdictal y la usucapión —esta última se entiende excluída en razón de textos como Gayo II, 93-.

El usufructuario se encuentra privado, durante la época clásica, en caso de expolio, de utilizar el interdictum unde vi, porque possidere eumnon videtur, y además, propie deiectus dici non potest (nos dice Vat. Fragm. 91) - ya que para la concesión del interdicto se está condicionado al hecho de la deiectio y esta situación, a su vez, está ligada a la existencia de la possessio_ - así comprobamos en textos como D. 43, 
16, 1, 23 interdictum autem hoc nulli conpetit nisi ei, qui tunc cum deiceretur possidebat, nec alius deici visus est quam qui possidet, y en D. 43, 16, 1,9 (Ulp. Lib.. LXIX ad Ed.) deicitur is, qui possidet, sive civiliter, sive naturaliter possideat; nam et naturalis possessio ad hoc interdictum pertinet.

De igual forma, y por estas mismas razones, al usufructuario no le afecta, desde un punto de vista pasivo, el interdicto quod legatorum que tiene una clara naturaleza posesoria $^{17}$. En definitiva existe una imposibilidad absoluta, durante la época clásica, de utilizar, en este campo, la terminología posesoria, no existiendo muestras de ninguna de las dos acepciones de la «quasi possessio», la «quasi possessio iuris» y la «quasi possessio rei».

Independientemente a estas consecuencias, debemos también indicar que, en un momento posterior —evidentemente no clásico a lo más postclásico—, el pretor flexibiliza las rígidas consecuencias de los principios clásicos, a través de conceder en vía útil al usufructuario los interdictos posesorios unde vi y uti possidetis (Vat. fragm. 90 y 91) —que pacíficamente se consideran manipulados-; aunque esta concesión en vía útil confirmaba, en definitiva, la falta de la cualidad estricta, en el poseedor, de la titularidad de los interdictos.

Esta cuestión se encuentra pacíficamente admitida por la mayor parte de la doctrina. Sin embargo puede ser, y efectivamente se discute, si la concesión de los interdictos de naturaleza posesoria (extendidos en vía útil) al usufructuario conducían, a estos mismos juristas, a una asimilación del usufructuario en el poseedor, a través de la nueva figura de la quasi possessio que encontramos en varios pasajes de la compilación.

La expresión quasi possessio, en estas sedes, ha sido por un nutrido grupo de estudiosos ${ }^{18}$ considerada como un glosema producto de la labor de los compiladores justinianeos —así como las palabras aut quasi possessione que se encuentran incorporadas en varios pasajes de Gayo.

Sin embargo, y a pesar de considerar como válida esta crítica interpolacionista, existen consideraciones, dentro de esta elaboración doctrinal, que no se pueden indicar como igualmente correctas: la identificación plena y constante de la quasi possessio del pasaje de Gayo con la quasi possessio iuris de otros pasajes también interpolados -identificación que induce a ALBERTARIO a establecer una «perfecta proporción» entre el pasaje de Gayo y los textos en los cuales la quasi possessio, en su enunciación genérica, designa a la quasi possessio iuris, como ocurre en: D. $4,6,23,2$; D. 8, 5, 10; D. 7, 1, 20-ya anteriormente citados- ${ }^{19}$; mientras que, por el diferente plano sobre el que estas situaciones están determinadas, el hecho que en

\footnotetext{
${ }^{17}$ Como se desprende del Vat. fragm. 90; como también lo indica ALBERTARIO en Studi II, pag. 371 y ss; SCHERILLO en Rend. Ist. lomb. 63 (1930) pag. 525.

${ }^{18}$ ALBERTARIO, Studi II, pag. 324, 361, 383 y ss.; así como PEROZZI I modi pretori di acquisto delle servitú, cit. pag. 65 y ss.

${ }^{19}$ Estudiados ampliamente por ALBERTARIO en Studi II, pag. 365.
} 
estos pasajes la quasi possessio haya sido introducida por los compiladores, no autoriza a considerar como no genuina esta expresión también en todos los textos donde ella se indica — no puede ser acertada esta coordinación, no se puede decir, que esta crítica tenía una perspectiva uniforme, cuando ha afirmado la imposibilidad de conciliar la quasi possessio del Gayo IV 139 con las repetidas afirmaciones de la falta de la cualidad de poseedor en el usufructuario, como se encuentran en las Instituciones de Gayo y fuera de ellas.

Así lo comprobamos en el ya citado Gayo IV 139:

Ceteris igitur ex causis praetor aut proconsul principaliter auctoritatem suam finiendis controversiis interponit, quod tum maxime facit, cum de possessione aut quasi possessione inter aliquos contenditur; et in summa aut iubet aliqui fieri aut fieri prohibet, formulae autem et verborum conceptiones, quibus in ea re utitur, interdicta decretae vocantur.

A tal punto, para determinar la quasi possessio del pasaje de Gayo se debe llegar, tal como hace CARCATERRA ${ }^{20}$ a concluir que no existe ninguna contradicción entre el párrafo 139 y aquellos otros pasajes en los que Gayo declaraba que el usufructuario non possidet, o recordaba la habitatio, así como el mismo usufructo, entre los casos de possessio detenta per quem libet qui nostro nomine sit in possessione - Gay IV, 153-. Afirmando que, de otra parte, la fórmula quasi, indicada por ALBERTARIO como sospechosa, «é attestata nelle Institucione di Gaio non meno di 38 volte» y en numerosas ocasiones el jurista se sirve de ella para «mostrare l'analogía di un fenomeno giuridico rispetto ad un istituto col quale nos ha niente a che vedere, col quale anzi, é in antitési» al punto de considerarla - la quasi possessiocomo una expresión con un contenido puramente negativo, llegando a establecer que: la analogía que aparecería no es una analogía jurídica, ni técnica, ni sustancial, todo lo más procesal ${ }^{21}$. Sin embargo una similar conclusión de la fórmula de Gayo no parece posible para la expresión quasi possessio, Gayo no podía escribir que el pretor autoritatem suam finiendis controversiis interponit... cum... de quasi possessione... contenditur. - El acento a las controversias procedentes de la expresión quasi possessione no puede ser genuino.

La expresión quasi possessio indicaría una especie de posesión cualificada, tal como dice BONFANTE ${ }^{22}$, una relación con la cosa no paralela sino análoga a la posesión, pudiendo también constituir una atrayente construcción dogmática, aunque no esté demostrado que corresponda puntualmente a las pautas establecidas por la jurisprudencia de la época clásica, ni con el genuino pensamiento de $\mathrm{Gayo}^{23}$.

${ }^{20}$ CARCATERRA, opus cit. pag. 64 y ss. donde concluye que la quasi possessio, en este pasaje de Gayo, tiene un valor puramente negativo «non é una possessio, anzi é un rapporto antitético al possesso -é detenzione-》.

${ }^{21}$ CARCATERRA, Il possesso dei diritti, cit. pag. 72 .

${ }^{22}$ BONFANTE, Corso III, cit. pag. 165.

${ }^{23}$ ALBERTARIO, Studi II cit. pag. 121. 
Y aunque Bonfante lo considera la quasi possessio del pasaje gayano no como una quasi possessio iuris, sino más probablemente como el disfrute de hecho de la plena possessio, sin embargo sospecha otras alternativas: «non si escluce che anche Gaio, con le parole de possessio aut quasi possessione abbia inteso distinguere tra posseso di cose incorporali: in altri termini, abbia veramente parlato di quasi possessio nel senso di possesso dei diritti».

Una construcción similar también se manifiesta en aquellos textos que no dudan en calificar como possessio la posición del usufructuario, aunque tan sólo sea conceptuándola dentro de aquellos límites que son para los justinianeos considerados como de la ínfima posesión, la possessio naturalis.

Asílo comprobamos en D. 41,2,12 pr.(Ulp.Lib. LXX ad ed.) Naturaliter videtur possidere is qui usum fructum habet.

El texto no está necesariamente interpolado, para un jurista clásico decir: naturaliter videtur possidere, era como determinar que no se tenía la posesión, sino tan sólo la detentación; a pesar de ello esta consideración asume en la compilación un significado diferente y más amplio de aquél que podía tener en su contexto originario, transformándose en una máxima general, a través de la cual se reconoce al usufructuario la posesión, al menos naturalis —recordemos que la terminología justinianea no consideraba esta situación válida para fines de usucapión ${ }^{24}$.

Un texto clave para determinar el origen no clásico de la quasi possessio en sus dos acepciones es el D. 4, 6, 23, 2:

D. 4, 6, 23, 2 (Ulp. Lib. III ad ed.) Item ei, qui per captivitatem fundi possessionem, vel ususfructus quasi possessionem amisit, succurrendum esse Papinianus ait; et fructus quoque medio tempore abalio ex usufrcutu perceptos debere aptivo restitui aequum putat.

En este pasaje no se habla de quasi possessio de la res por parte del usufructuario, sino de quasi possessio usufructus; la expresión toma aquí relieve en cuanto está en contraste con otra possessio fundi, se constituye un simétrico paralelismo: al ejercicio de hecho del poder sobre la cosa le correspondería la expresión possessio - aunque su especificación más rigurosa sería quasi possessio rei-, mientras que al ejercicio de hecho del derecho de usufructo le corresponde la expresión quasi possessio - ambigua expresión que subsume la enunciación de quasi possessio iuris.

Evidentemente, y en base a las mútliples afirmaciones de la imposibilidad de poseer las cosas de naturaleza incorporal, esta construcción no pudo ser debida a la labor de los juristas de la época clásica.

En este D. 4, 6, 23, 2, (Ulp. Lib. XII, ad Ed.) si consideramos el tratamiento de Ulpiano al examinar la aplicación al captivus del edicto pretorio sobre la integrum

\footnotetext{
${ }^{24}$ Respecto a este propósito ver también junto a Albertario en Studi II pag. 154 a Scherillo Rend. Inst. Lob.. 1930, 525 n. 4 así como Maschi La concezione naturalistica del diritto pag. 114.
} 
restitutio, se comprueba que el problema examinado en el texto es, por un lado la conservación y la readquisición de la posesión, y por otro el cumplimiento de la usucapión. Así, en el párrafo primero se establecen unos firmes puntos: qui apud hostes est no puede coesptem possessionem implere, como tampoco puede nadie, a través del postliminum, readquirir la posesión y remprender la usucapión interrumpida.

Sin embargo, a pesar de las anteriores consideraciones, en el párrafo tercero - de este mismo pasaje - se examina la posición de quién se encontraba in potestate captivi, al cual se le permite usucapir ex peculiari también durante el cautiverio.

En coherencia Ulpiano no habría podido escribir que aquel que perdía, a causa de caer como prisionero de guerra, la possessio fundi o la quasi possessio usufructus era cosa justa restituir los frutos que, durante este espacio de tiempo - se entiende durante el tiempo del cautiverio-, habían sido percibidos por otro. No habría podido realizar esta elaboración ya que a la possessio no se le aplica el postliminio, como el mismo Papiniano establece en

D. 4,6, 19 (Papinianus. Lib. III.Quaestionum) Denique si emtor, priusquam per usum sibi acquireret, ab hostibus captus sit, placet interruptam possessionem postliminio non restitui, quia haec sine possessione non consistit, possessio autem plurium facti habet, causa vero facti non continetur postlimino, contradicción que anula la tesis que se orienta hacia el posible origen clásico de la expresión.

Sin emabrgo esta elaboración tiene varios flancos criticables, en el D. 4, 6, 23, 2 no se hace cuestión del postliminum, ni siquiera como vía de la afirmada restitución de los frutos: Papiniano sostenía únicamente la oportunidad de venir en auxilio del captivus y de acordarse la restitución de los frutos en base a un principio de equidad:

D. 4, 6, 23,2 (Ulp. Lib. XII, ad Ed.) sucurrendumesse Papinianus ait, et fructus... debere restitui aequum putat. (Situación que se ignora, inexplicablemente, en el análisis que ALBERTARIO realiza de este pasaje).

Con todas estas hipótesis, el contraste entre el D. 4, 6, 32, 2 y todos los textos precedentes aparece ahora más estridente y anormal, ¿cómo justificar una argumentación sobre el usufructo mientras que el comentario de Ulpiano está totalmente dedicado, en este punto, a la possessio y a la usucapión?

Parece concluirse que tanto la referencia a la quasi possessio usufructus, cuanto la sucesiva a la ex usu fructu han sido incluidas por los compiladores; el texto original se ocupaba sólo de la possessio fundi, y sólo después de haberla puesto en relieve, se pueden concluir varias premisas en relación con el fragmento primero: que el prisionero pierde la posiblidad de continuar poseyendo y de completar la usucapión; que por otro lado, no readquiere esta posibilidad nadie a través del postliminium, sino que se pasaba a considerar la posibilidad de recuperar los frutos por parte del captivus — que habían sido percibidos por otro-, posibilidad que se reconocía aplicando un criterio de equidad - a este respecto se puede recordar la opinión de Bartolo que destaca la íntima relación que existe entre el fragmento primero y 
segundo destacando que tanto el uno como el otro hacen referencia al problema de la usucapión, así decía "captus ab hostibus non test usucapere: et rusus ad hoc non restituetur sed restituetur ut fructus recuperet» es decir, en el texto no se habla de usufructo sino de posesión.

¿Por qué los compiladores habían sentido la necesidad de introducir en este texto la mención del usufructo? La respuesta no parece difícil: los compiladores daban relieve al paralelismo entre la posesión de la cosa y el ejercicio de hecho del derecho; de otra parte el contexto se prestaba a hablar de usus - aunque para Ulpiano se trataba del usus que conducía a la usucapión, de usu adquirire - de adquisición y de restitución de los frutos: de esta manera, una inserción de la quasi possessio ususfructus podía ser hecha sin dificultad en este entorno.

Parece claro que son los justinianeos los que introducen, junto a lapossessiofundi, la quasi possessio usufructus, considerada ésta como è ejercicio de hecho del derecho de usufructo, cualificado a través de una terminología de naturaleza posesoria.

Sobre este punto podemos concluir que la jurisprudencia clásica —en el tema del usufructo, y correlativamente en las servidumbres prediales - se plantea un problema: ¿cuál es la posición del usufructuario en las relaciones con la cosa objeto del usufructo?. Y lo resuelven excluyendo la posesión, relegando al usufructuario a la categoría de los detentadores, así como confirmando que el usufructuario detenta la cosa nomine alieno.

Esta neta posición dogmática no impide que el pretor, bajo exigencias evidentemente prácticas, extendiese al usufructuario, en vía útil, los interdictos que protegían a la possessio; aunque tal extensión no significaba una nueva posición de la doctrina —que permanecía fiel al principio por el que se prohibía la posesión de las cosas incorporales, entre ellas a los derechos-, sino una primera adaptación, únicamente vinculante en el campo procesal.

Sin embargo en éste, como en otros campos, era inevitable que la equiparación procesal condujese a una equiparación también sustancial, aún más cuando la distinción entre competencia directa y concesión en vía útil vino a anularse, a la vez que cesaba la estricta vigilancia de la jurisprudencia clásica.

Será de esta forma como los anotadores postclásicos, no con un determninado y claro intento de reforma, sino a través de la interpretación de los textos jurisprudenciales —en los que encontramos concedidos en vía útil los interdictos posesorios-, son dados a resumir estas nuevas situaciones, en la fórmula de la quasi possessio, que era, desde un punto de vista práctico, una asimilación a la possessio, mientras que implicaba, en el terreno dogmático, una neta diferenciación y contraposición respecto de su objeto.

Los juristas justinianeos reemprendieron esa asimilación y la condujeron a sus extremas consecuencias, atribuyendo al usufructuario la quasi possessio rei y al cesionario del derecho de usufructo la quasi possessio iuris con todas sus consecuencias prácticas. 
Esta peculiar evolución de los institutos posesorios en el ámbito de los derechos fue comprendida, de forma clara, por la escuela bizantina. Teófilo considera que es errónea la doctrina que atribuye únicamente la possessio al usufructuario ${ }^{25}$, él se sirve de la expresión quasi possessi, para distinguir entre la posesión de las cosas materiales (Kaì nomé megèsti sōmetiloū) y la posesión de derechos (ōsameì dè gynè estìn asōmotos xaésis)), como deduce de Teófilo. Par., IV, 15 pr., distinguiendo entre la quasi possessio rei y la quasi possessio iuris.

Más tarde, en el Epitome, la distinción está más claramente definida entre la possessio rei corporalis —en su cualificación de -quasipossessio rei-y la possessio rei incorporalis -o quasi possessio iuris-, superando, decisivamente, la media luz que ofrecía la ambigua enunciación de la quasi possessio ${ }^{26}$.

Comprobamos que la escuela bizantina ha dado relieve al segundo de los aspectos de la transformación de los conceptos clásicos realizada por los compiladores justinianeos, es decir, el concepto del ejercicio de hecho de un derecho de usufructo —cualificando esta situación como una possessio iuris-, concepto que desarrollan hasta llegar a la distinción —que también se encuentra en el Epitome- entre la possessio rei corporalis y possessio rei incorporalis.

Su posible ambigüedad, procedente de a veces identificar la quasi possessio y la possessio iuris, tiene menor relieve dentro de los bizantinos - principalmente en Teófilo-, que supieron sin embargo distinguir los diversos significados que el término quasi possessio englobaba en la compilación justinianea.

Para ellos la expresión quasi possessio iuris significaba no la posesión del derecho del que se es titular, es decir, la posesión del titular del propio derecho de usufructo de uso o de habitatio: muy al contrario, era el ejercicio de hecho del derecho del que no se tiene la titularidad, fundamentalmente por la falta de una válida constitución.

De forma más precisa en el usufructo, acentuaron, aún con mayor incidencia que los compiladores jutinianeos, la distinción entre el derecho que (Kyrios sygistatai) y aquel constituido (Katà Xnēstikw̄s dia tradítionos), del cual se tiene sólo el ejercicio de hecho y que se pierde con el no ejercicio ${ }^{27}$.

Bien clara es también la influencia de la quasi possessio iuris en el campo de las serivdumbres prediales, donde podemos también distinguir los diferentes contenidos de las expresiones quasi possessio rei y la quasi possessio iuris con sus diversas repercusiones jurídicas.

En las servidumbres prediales el proceso de transformación operado por los compiladores sobre los textos clásicos, para introducir el nuevo concepto, se observa en las condiciones ideales, fuera de todo tipo de perturbaciones.

En las servidumbres prediales, donde el titular está fuera de todas las relaciones,

${ }^{25}$ Teófilo, Par, II, 9, 4.

${ }^{26}$ Epitome, Zachariae, Ius graeco-romanum, II, 3, 15.

${ }^{27}$ Bas, XV, 11 Schol, 10 ad h. 1. 
no sólo de señoría, sino también de simple detentación con el fundo sirviente, donde, evidentemente, no se pueden establecer cuestiones de possessio rei; no existe la posibilidad para el derecho justinianeo, no más que para el derecho clásico, de tratar al titular de una servidumbre predial como un poseedor de la cosa.

El problema que podemos examinar en este terreno es aquel de la posición de quién ejercita de hecho una servidumbre non iure constituta, situaciones que serán el núcleo que justifica la quasi possessio iuris.

La jurisprudencia clásica que veía la posesión sólo donde existía una relación con una res corporalis (D. 41,2,3), excluye coherentemente que las servidumbres puedan ser poseídas —este principio está formulado directa y expresamente en D. 8, 2, 32 (Iulianus. Lib. VII Digestorum): natura servitutium ea est ut possideri non possint-; así como también se prohibe la usucapibilidad (D. 8, 1, 14 pr. y la aplicación de la traditio (en los D. 19, 1, 3, 2; D. 8, 1,20), sin embargo, no ignoraba el fenómeno de su ejercicio de hecho - ejemplos de ejercicio de hecho de las servidumbres non iure constituae por falta de su forma solemne lo encontramos en D. 43, 26, 2, 3; D. 43, 19, 3, 2; D. 8, 1, 20; D. 19, 1, 3, 2 .

Si bien el derecho clásico no sentía la necesidad de una especial disciplina para el ejercicio de hecho del usufructo, si la sentía, por el contrario, en cierta medida para la servidumbre. Las dos situaciones son en realidad diferentes: el usufructuario adquiere la material disponibilidad de la cosa sobre la cual ejercita su derecho, mientas que, en el campo de las servidumbres prediales, su ejercicio limitaba sólo parcialmente el poder del dominus sobre la cosa.

Esta posición es fruto de los elementos que los justinianeos han omitido eliminar, textos donde se destaca, sobre todo, la formulación que el pretor daba para proteger el ejercicio de hecho de la srvidumbre, sobre el fundamento del usus: quo itinere actuque privato vel via... nec vi nec clam nec precario ab illo usus es, quo minus ita utaris...-como se lee en D. 43, 19, 1 pr. (Ulp. Lib. LXX ad Ed.) así como en D. 43, 22, 1 pr. (Ulp. Lib. LXX ad Ed.) uti de eo fonte... aqua nec vi nec clam nec precario ab illo usus en quominus ita utaris... ${ }^{28}$

Los compiladores renovaron profundamente la construcción clásica, introduciendo en lugar de la noción del usus iuris (propio del derecho clásico) el concepto de la qudsi possessio servitius.

De esta forma, donde se hablaba de un ejercicio de hecho de un derecho, los clásicos estaban obligados a usar las expresiones inadecuadas de possessio rei y usus iuris, como se desprende de la presencia, en los textos de la alternativa ut sibipossidere aut ut sibi liceat, mientras que los compiladores han hecho desaparecer el usus iuris y hablan de possessio vel corporis vel iurs en D. 43, 26, 2, 3 (Ulp. Lib. LXXI ad Ed. $)^{29}$. Una primera consideración terminológica-posesoria en el campo de las servidumbres prediales.

\footnotetext{
${ }^{28}$ Para una más amplia indagación sobre este punto se debe considerar ALBERTARIO, Studi, II, pag. 339 y ss.

${ }^{29}$ Estudiado por ALBERTARIO Studi II, pag. 340.
} 
De idéntica manera, frente a una categoria claramente planteada por los juristas clásicos bajo el perfil del usus (si quis ab auctore meo vi aut clam aut precario usus est), los compiladores sintieron la necesidad de motivar: quia a me videtur vi vel clam vel precario possidere qui ab auctore meo vitiose possidet, como una repetición que, sería inútil y banal si no fuera destinada a mutar profundamente la base de la propia construcción clásica.

En este sentido es como se interpretan textos como D. 43, 19, 3, 2 (Ulp. LIb. LXX. ad Ed.)

Si quies ab actore meo vi, aut clam, aut precario usus est, recte a me via utiprohibeatur, et interdictum ei inutile est, quia a me videtur vi, vel clam, vel precario possidere, qui ab actore meo vitiose possidet. Nam et Pedius scribit, si vi, aut clam, aut precario ab eo sit usus, in cuius locum hereditate, vel emtione aliove quo iure successi, idem esse dicendum; quum enim successerit quis in locum eorum, aequum non est, nos noceri hoc, quod adversus eum non nocuit, in cuius locum successimus ${ }^{30}$.

Esta evolución se aprecia con más claridad en el caso de un ejercicio de hecho nec vi clam nec precario de una servidumbre de paso, donde a la decisión clásica inutile est ei interdictum de itinere actuque, los justinianeos adjuntaron la afirmación nam ut hoc interdictum competat ius fundi possedisse oportet como leemos en el casi correlativo D. 43, 19, 7 .

Hay otros casos donde la influencia de los compiladores es más profunda respecto a los planteamientos clásicos, haciendo desaparecer toda huella que se refiera al usus iuris, poniendo de relieve únicamente la possessio ${ }^{31}$, cuando no, establecían directamente ex novo una máxima que no tiene nada de clásica ni en la sustancia ni en la forma ${ }^{32}$, y en donde la noción de la possessio iuris tiene plenos efectos.

La conclusión de todo este proceso, alrededor del que los compiladores criticaban la construcción clásica del usus iuris, da como resultado una casi plena equiparación del ejercicio de hecho de la servidumbre, calificiado como possessio iuris, y la possessio rei de Derecho clásico.

Se produce una equiparación entra la quasi possessio iuris justinianea y la possessio rei clásica, equiparación que no se limitaba al campo terminológico, sino que conlleva efectos sustanciales por la extensión a la quasi possessio servitutis de algunas típicas consecuencias de la possessio: 1.- adquisición de la misma por el transcurso del tiempo, así la longi temporis praescriptio sustituye, en el derecho

\footnotetext{
${ }^{30}$ Analizado por ALBERTARIO en Studi II pag.. 342-343: además también por BONFANTE, Corso III, pag. 381-382.

- ${ }^{31}$ Como es el caso de D. 8, 4, 2 estudiado por ALBERTARIO, Studi II, pag. 241-242.

${ }^{32}$ Este es el supuesto de D. 43, 20,1,44, que ALBERTARIO, Studi II pag. 344, considera enteramente fruto de la creación justinianea, y sobre el que BERGER Miszellen aus der Interdiktenlehre en Z. S. S. 195, pag. 194-195, amplía las consideraciones de los compiladores.
} 
justinianeo, con función adquisitiva, a la función puramente presuntiva de la vetustas clásica $^{33}$. 2:- el reconocimiento de la eficacia de la traditio, así como la concesión de la publiciana como se lee en D. 6, 2,11, $1^{34}$. Respecto a la eficacia de la traditio en el campo de las servidumbres ocurre un fenómeno análogo al que afecta al usufructo: los juristas clásicos negaban la eficacia de la traditio como medio de constituir la servidumbre -así se desprende de textos como: D. 19, 3, 2 vacuae possessionis traditio nulla est, o en D. 8, 1,20 quia nulla eius odi iuris vacua traditio esset-y sólo se preocuparon de indicar, en la práctica, un medio que hiciese valer una relación que, dada la falta de forma, no podía tener una existencia jurídica. Este medio consistía, tanto para Pomponio como para Labeo, en una caución per te nos fieri quominus ire agere liceat en la creación, es decir una relación obligatoria en lugar de la relación real de servidumbre, que no puede surgir por defecto de forma. Los justinianeos, por el contrario, concedieron, como hicieron para el usufructo, la publiciana para tutela de la sevidumbre per traditionem constituae, otorgando a la traditio una eficacia real; no como un medio de constitución del derecho de servidumbre - proviniente de la expresión servitutes per traditionem constituaesino como origen de un estado de hecho de naturaleza posesoria al cual le viene acordado como protección la publiciana. 3.- cualifican los interdictos acordados para la protección de la servidumbre como interdicta veluti possessoria, así como la concesión de interdictos como el quod legatorum que requería, para su legitimación pasiva, la posesión. Como parece claro los justinianeos no llegaron a extender la tutela del ejercicio de hecho de las servidumbres los interdictos uti possidetis y el unde vi-ya que no se puede hablar de completa equiparación entre la quasipossessio servitutis y la possessio rei del derecho clásico- aunque consideraban como veluti possessoria los interdictos que el derecho postclásico acordaba —como se desprende del D. 8, 1,20-, así como aplicando el interdicto quod legatorum contra aquel que se había introducido en el ejercicio de una servidumbre sin el consentimiento del heredero ${ }^{35}$.

El desarrollo y la aplicación de los nuevos conceptos - quasi possessio iuris y quasi possessio rei- en este campo de las servidumbres prediales tenía una evolución orgánica y completa, ya que la posesión de derechos se configura —como se demuestra a través de las alteraciones de los textos clásicos- como una noción que individualiza y cualifica el ejercicio de hecho de una servidumbre de la que falta, por cualquier vicio de constitución, su válida titularidad por parte de quién de hecho la ejercita; influencia que se comprueba a través de la inclusión de este ejercicio dentro del campo terminológico, así como en el contenido intrínseco de la misma possessio, esto es, la posibilidad de su constitución a través de la traditio, la

\footnotetext{
${ }^{33}$ Ver PEROZZI opus cit. pag. 124, y ALBERTARIO en Studi II, pag. 351 y ss.

${ }^{34}$ Estudiado por ALBERTARIO opus cit. pag. 350.

${ }^{35}$ Véase en este sentido el contenido del ya analizado D. $43,3,1,8$.
} 
capacidad de interponer los interdictos posesorios para su protección; en definitiva una asimiliación no sólo formal sino sustancial con la clásica possessio.

Como conclusiones básicas de esta aproximación en torno a la terminología y naturaleza jurídica de la posesión de derechos podemos destacar que, a través de un amplio análisis de los textos clásicos y a vista de las interpolaciones de los compiladores justinianeos, y respecto a la institución del usufructo es posible reconstruir un doble proceso innovador de las concepciones clásicas, proceso que por un lado lleva a la transformación de la detentación, que en derecho clásico ligaba el usufructuario a la cosa, a la posesión, a través de la quasi possessio rei que los anotadores postclásicos habían introducido en muchos textos, y que respresenta el anhelo de conjunción entre los dos intstitutos; mientras que por otro lado se llega a la introducción de una tutela del usufructo non iure constitutus - considerada en época justinianea como una quasi possessio iuris-y cuyo objeto no es la cosa sobre la que recae el usufructo sino el contenido mismo del derecho de usufructo (el uti frui).

Estas concepciones no sólo afectaron al campo del usufructo, sino que tuvieron vigencia y eficacia en otros sectores: servidumbres, habitatio, etc. donde hay una amplia relación del sujeto con la cosa (un amplio disfrute de la misma) determinándose también, en estas situaciones, la doble perspectiva:

A. La posibilidad de existir una extensión de los interdictos posesorios a situaciones que durante la época clásica se consideraban imposibles de poseer: respecto del titular del derecho y sobre la cosa objeto del mismo, denominadas con la expresión quasi possessio rei.

B. La posibilidad, también durante la época justinianea, de proteger a aquel individuo que sin ser titular de uno de estos derechos ejercitaba el contenido de los mismos como si tuviera tal cualidad jurídica, protección que también se arbitrara en base a los interdictos de naturaleza típicamente posesoria, y que las fuentes denominaron como la quasi possessio iuris.

Esta distinción entre ambas perspectivas sin embargo no se produce de una forma nítida y uniforme encontrándonos textos que las utilizan sin una precisa determinación, mientras que será la lógica evolución del ordenamiento jurídico romano, y más en una institución que rompe, en cierta medida, criterios rígidamente establecidos en otras épocas (la imposibilidad de poseer cosas incorporales que en numerosos preceptos de la época clásica se establece), la que perfile los rasgos más netamente normativos de estas diferentes situaciones de hecho.

Fruto de estas confusiones terminológicas -que en los juriconsultos se aprecia a la hora de deslindar las peculiaridades de cada una de las figuras quasi possessio rei y quasi possessio iuris - es la configuración, por parte de la doctrina, de una difícil amalgama de situaciones que con frecuencia mezclan, sin distinción, supuestos de hecho de diferente e independiente naturaleza y regulación jurídica.

Consideraciones que se desprenden del análisis de algunos textos donde la 
expresión quasi possessio representa un concepto ambiguo y elástico, donde se recoge tanto la situación del titular del derecho en relación con la cosa sobre la que recae el mismo — quasi possessio rei-, así como la relación existente entre el contenido mismo del derecho y aquel individuo que lo ejercitaba de hecho careciendo de su válida titularidad — quasi possessio iuris. 